\title{
Iron-Catalyzed Cross-Coupling of Imidoyl Chlorides with Grignard Reagents
}

Lars K. Ottesen, Fredrik Ek, and Roger Olsson*

\section{SUPPORTING INFORMATION}

\section{Table of Contents}

Supporting information file one

General experimental paragraph

Experimental details

Supporting information file two

${ }^{13}$ C NMR

Supporting information file three (this file)

S3

S3-S15

${ }^{1}$ H NMR

S16-S38

S39-S61 


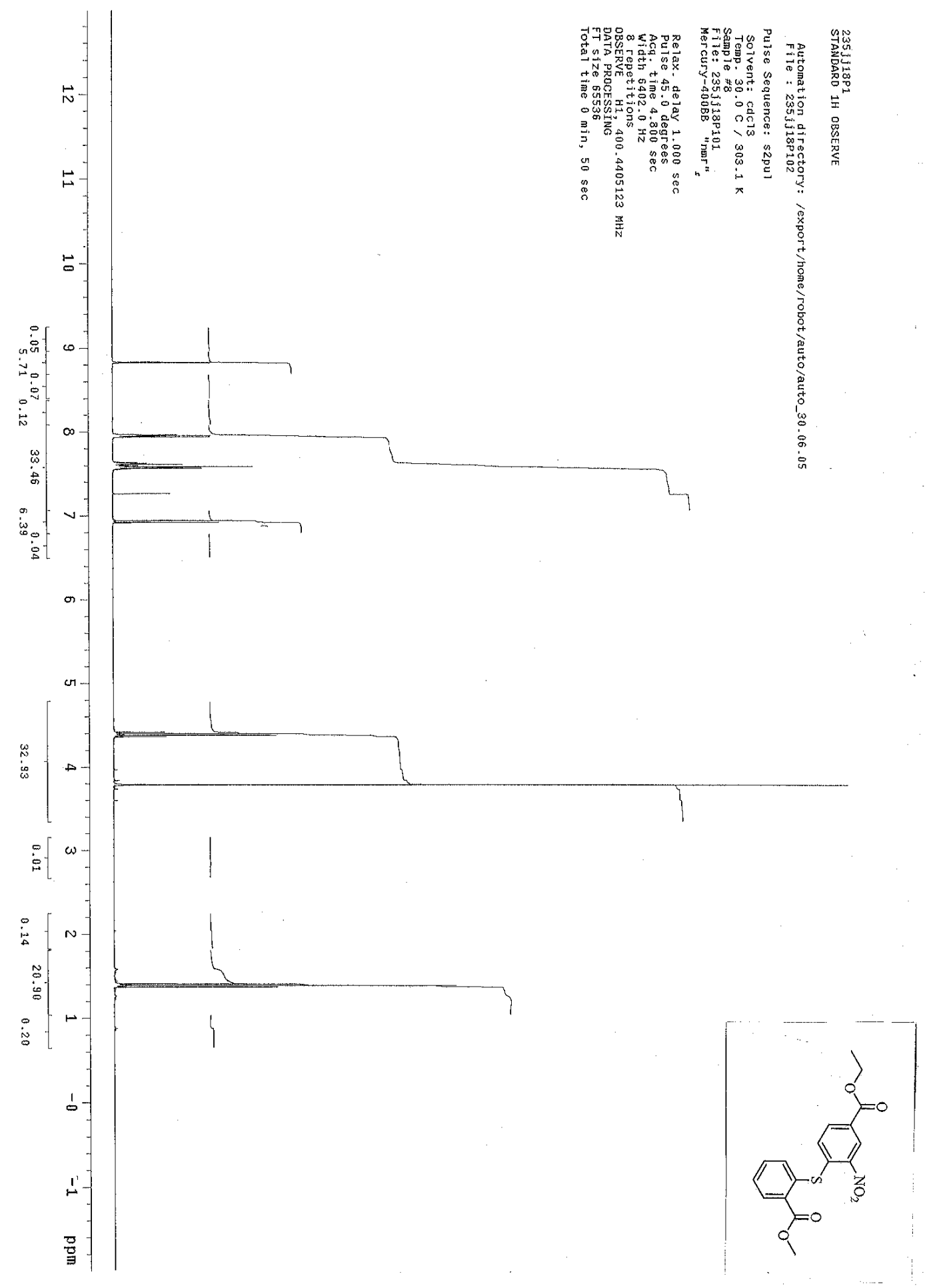




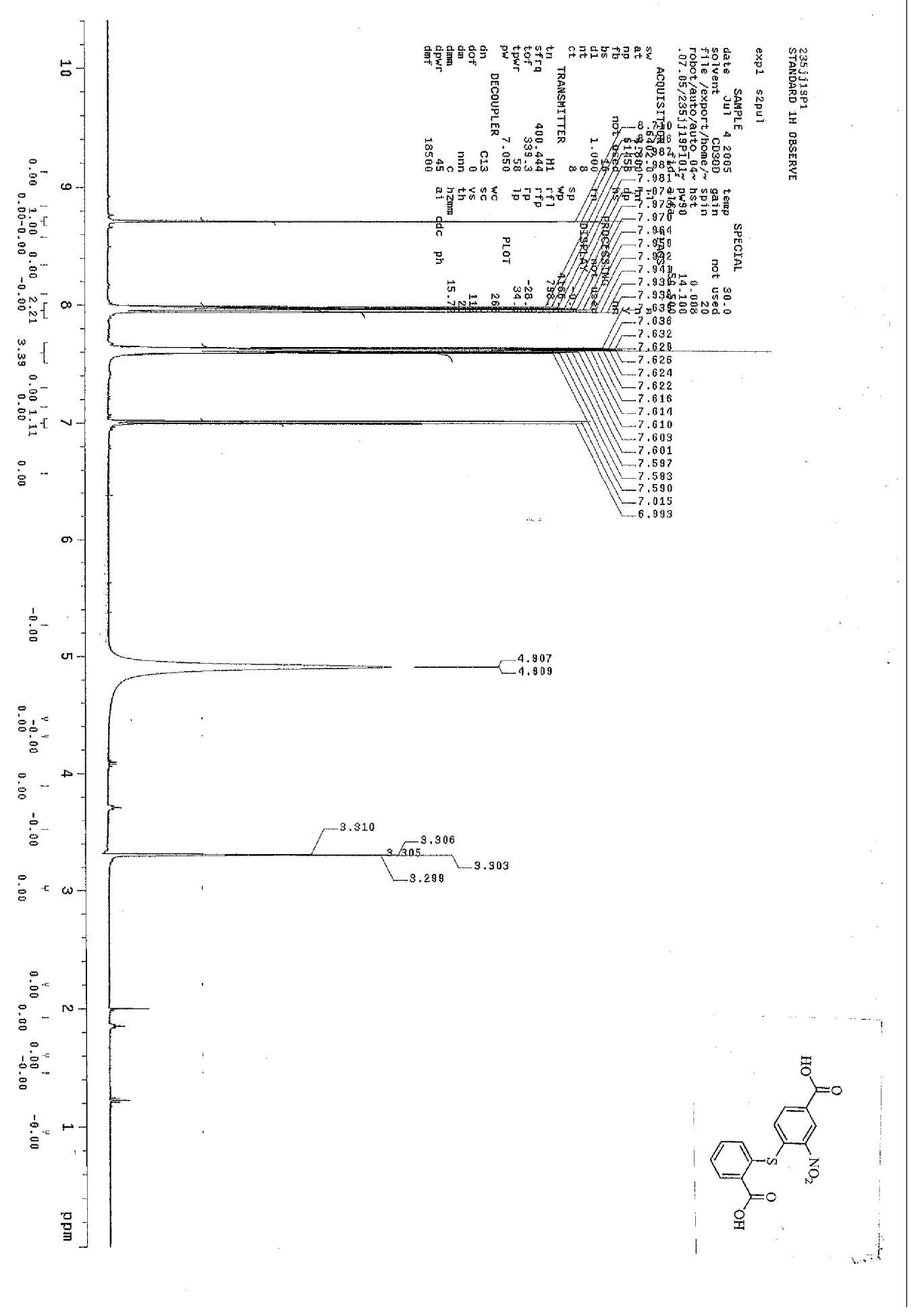




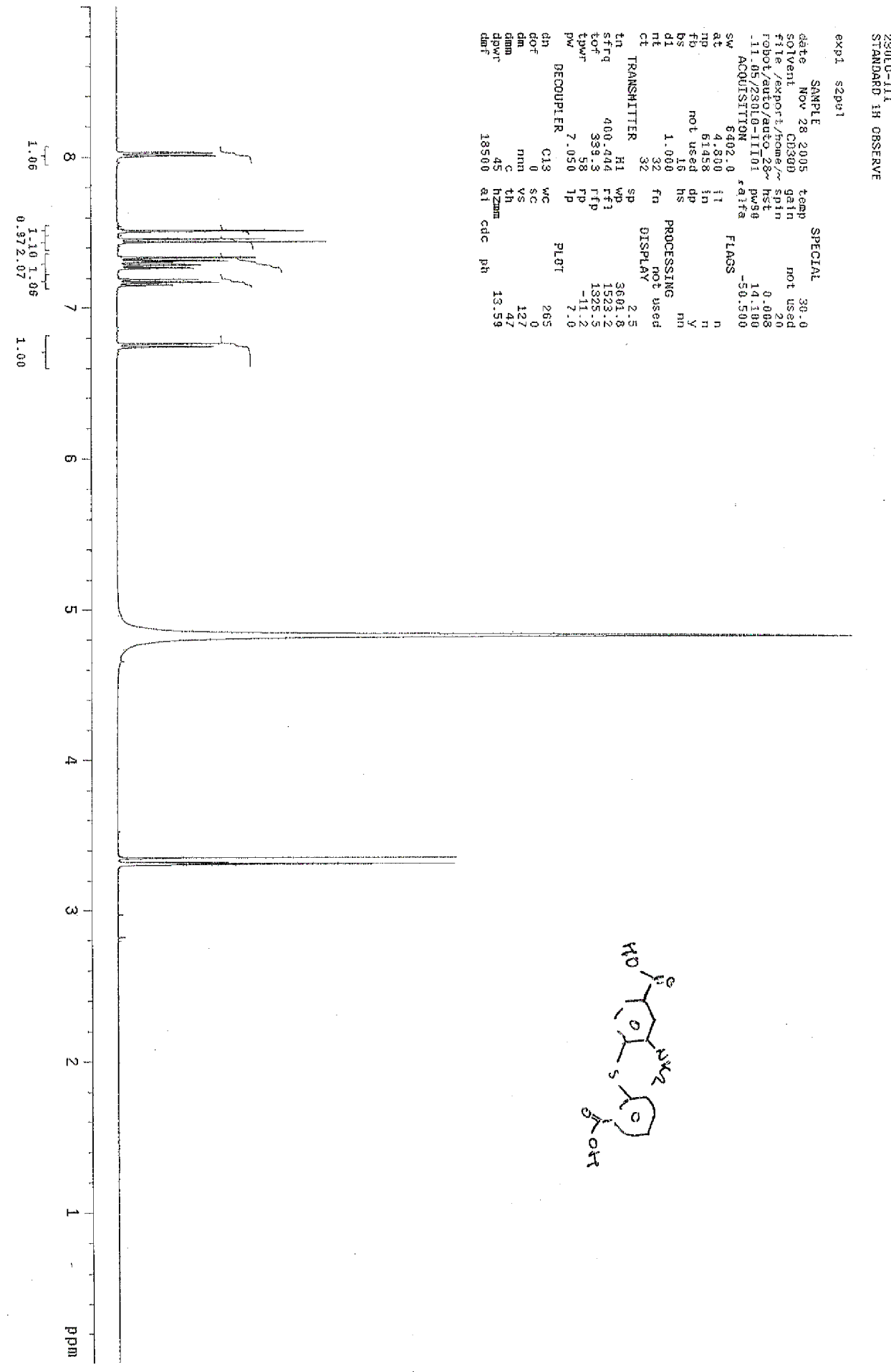




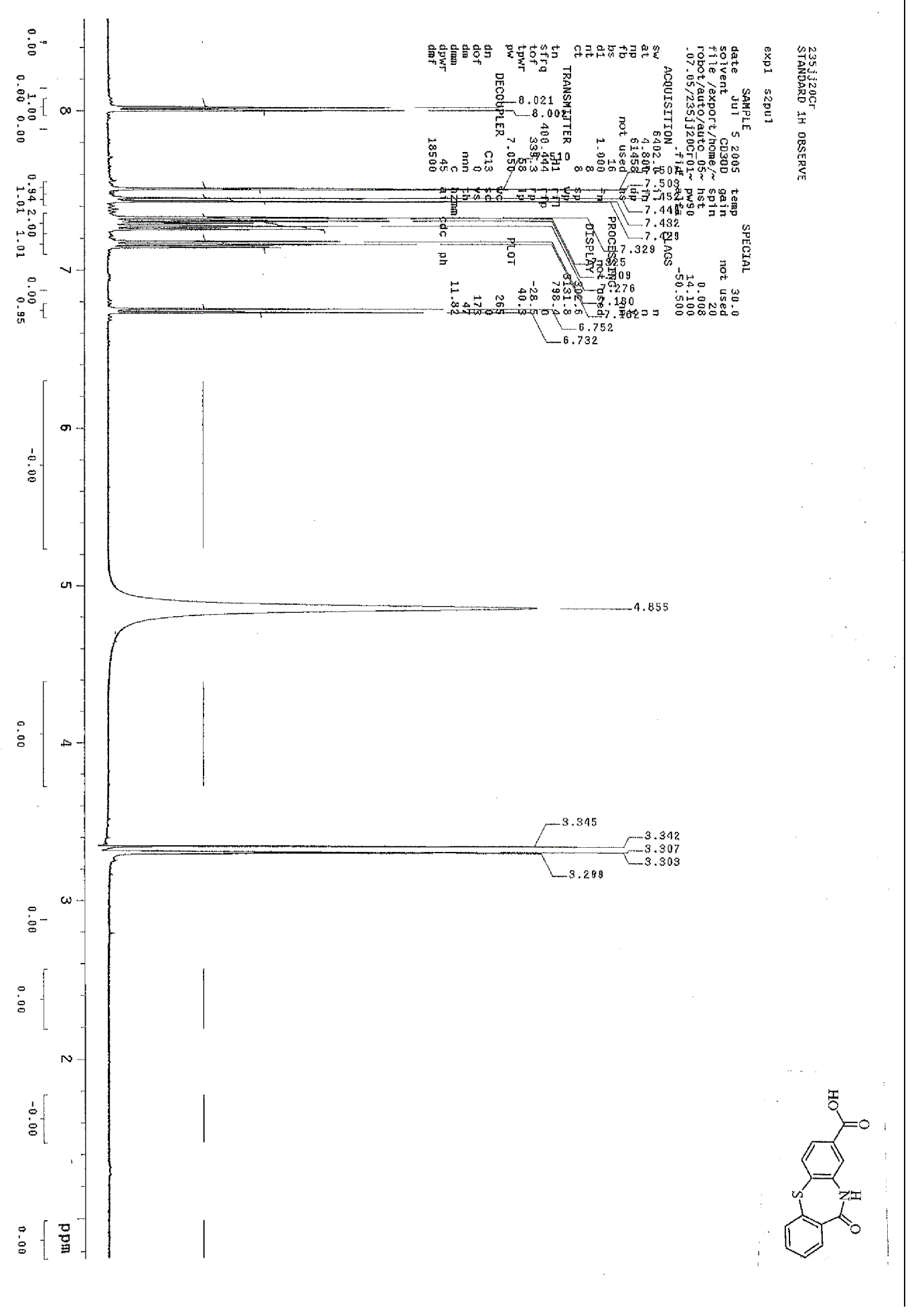




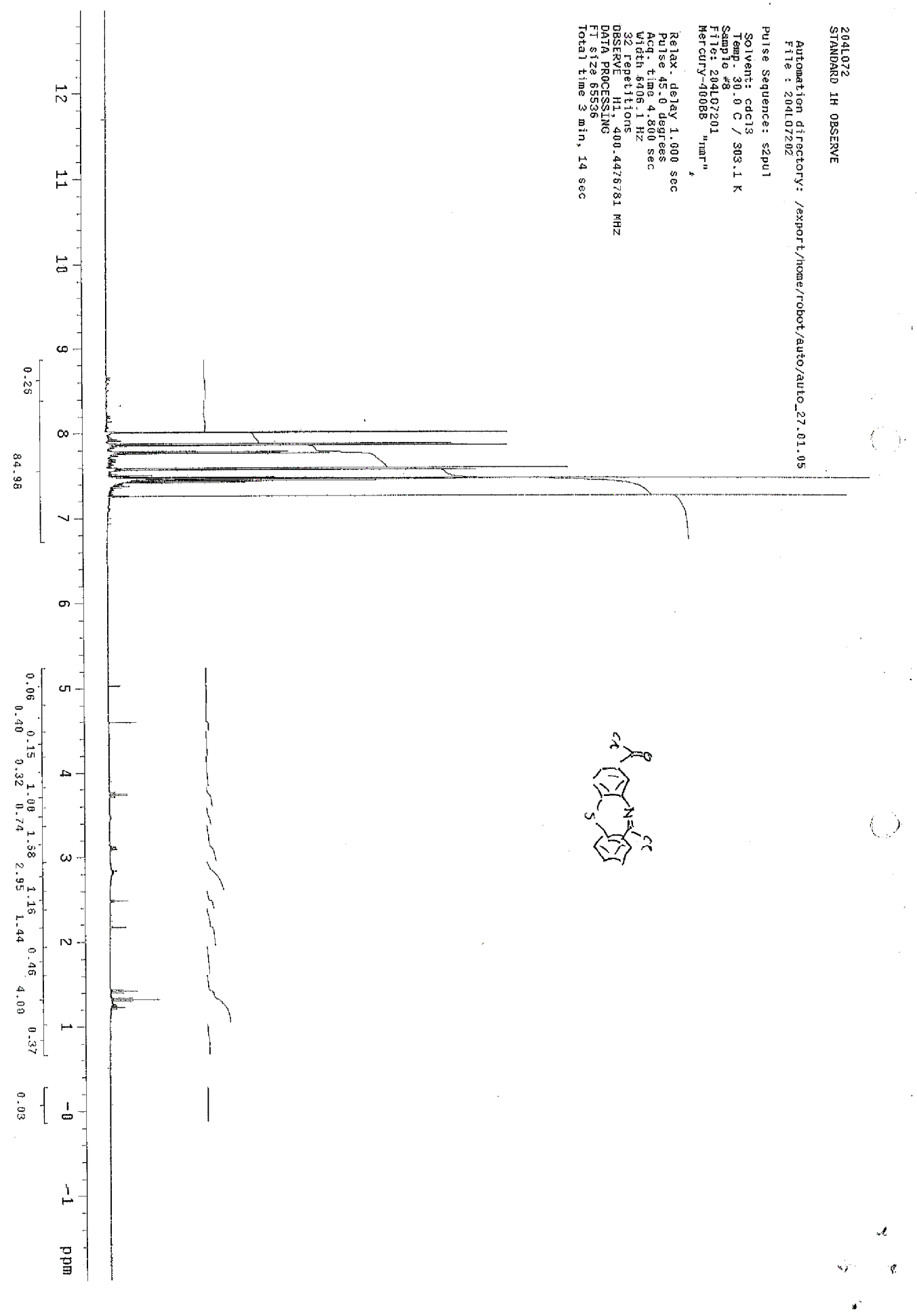



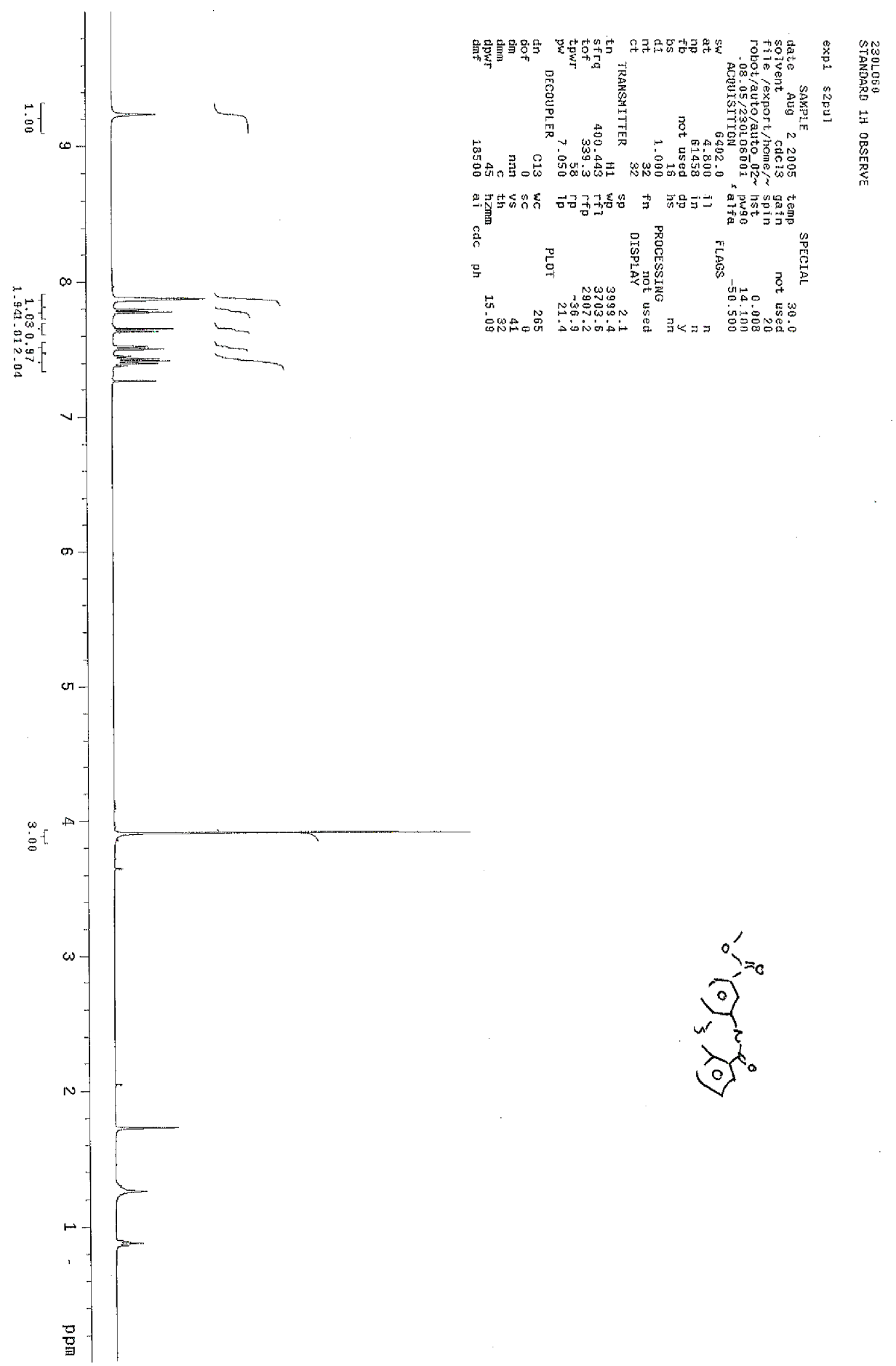

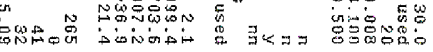




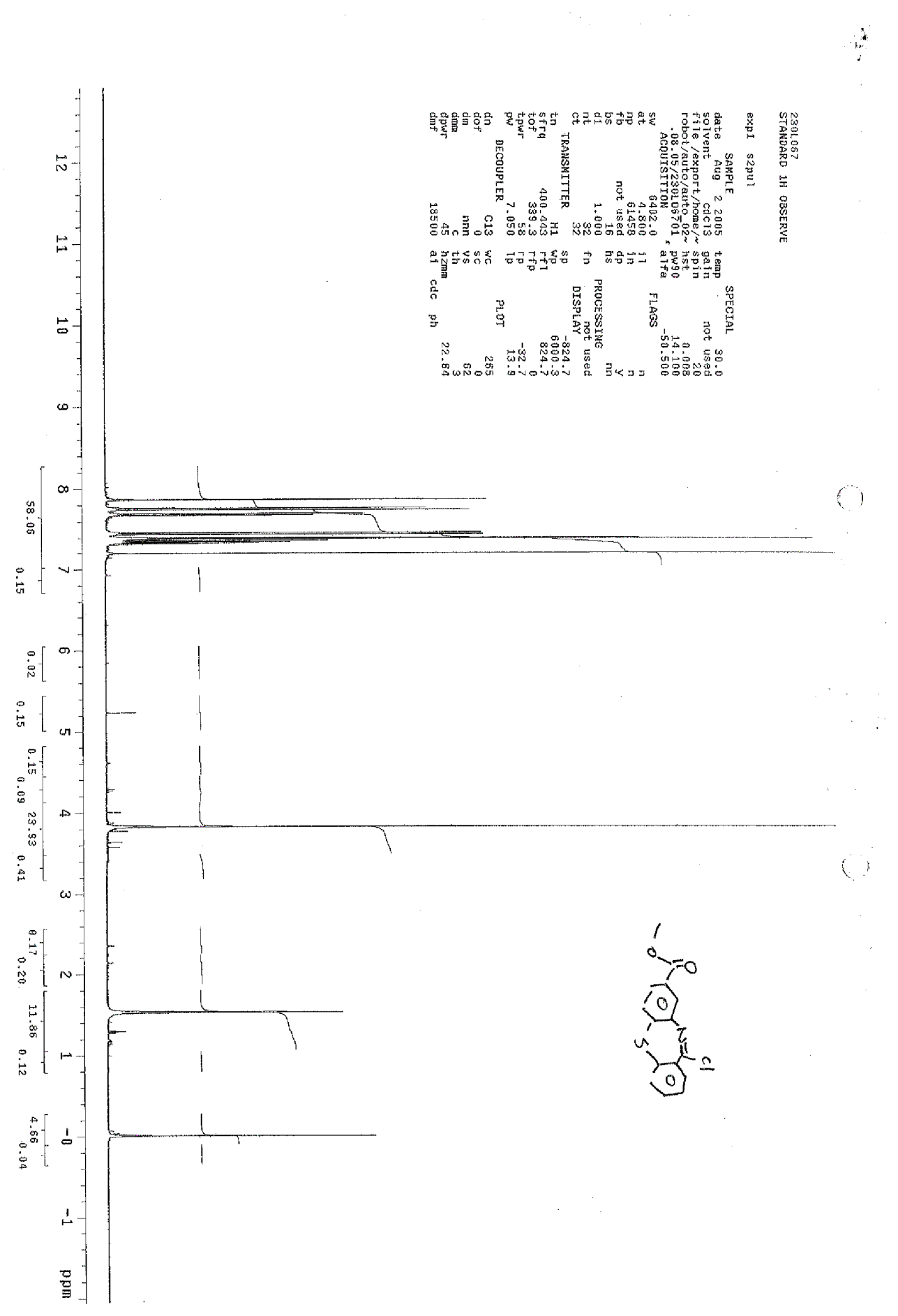




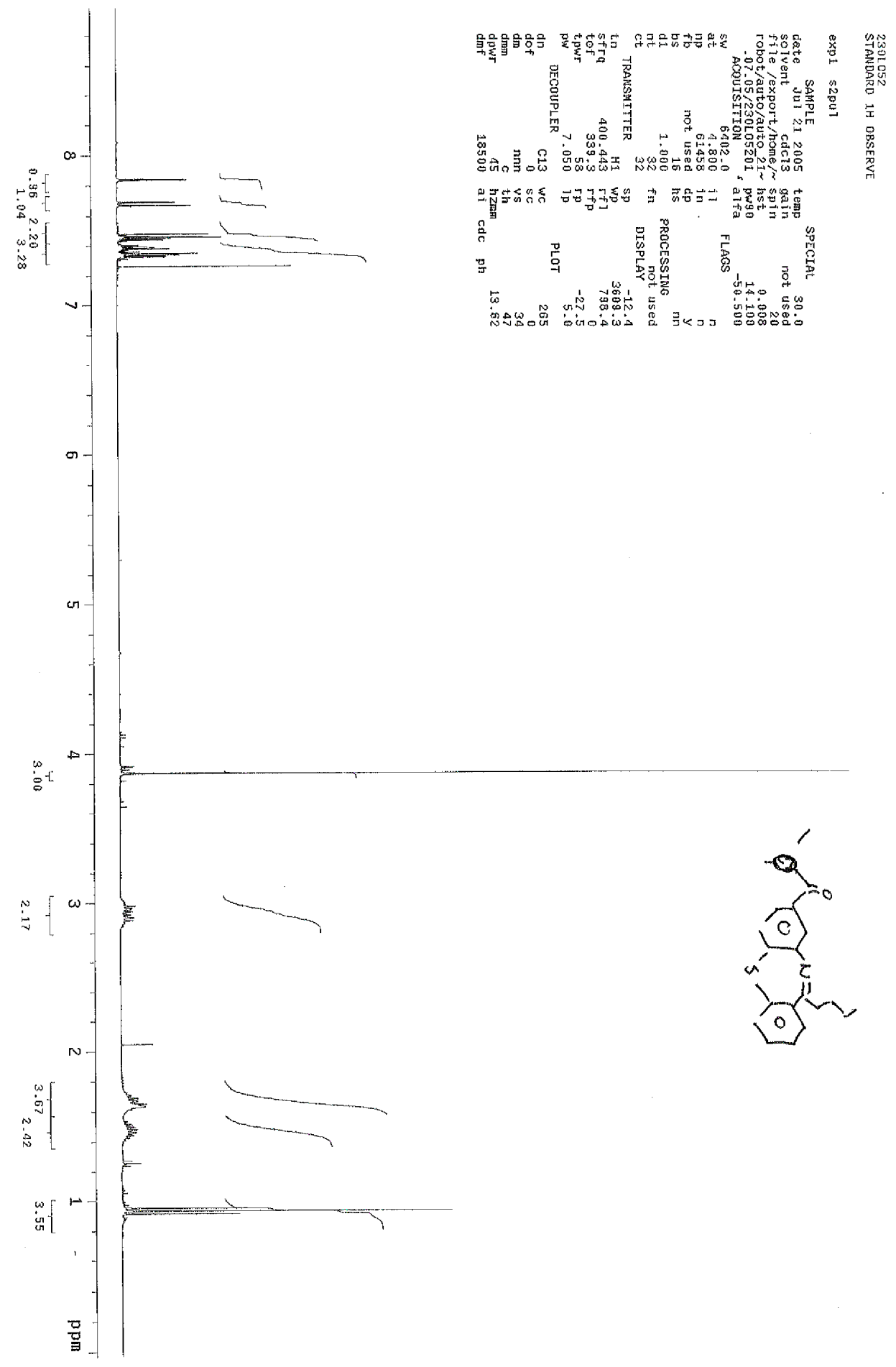




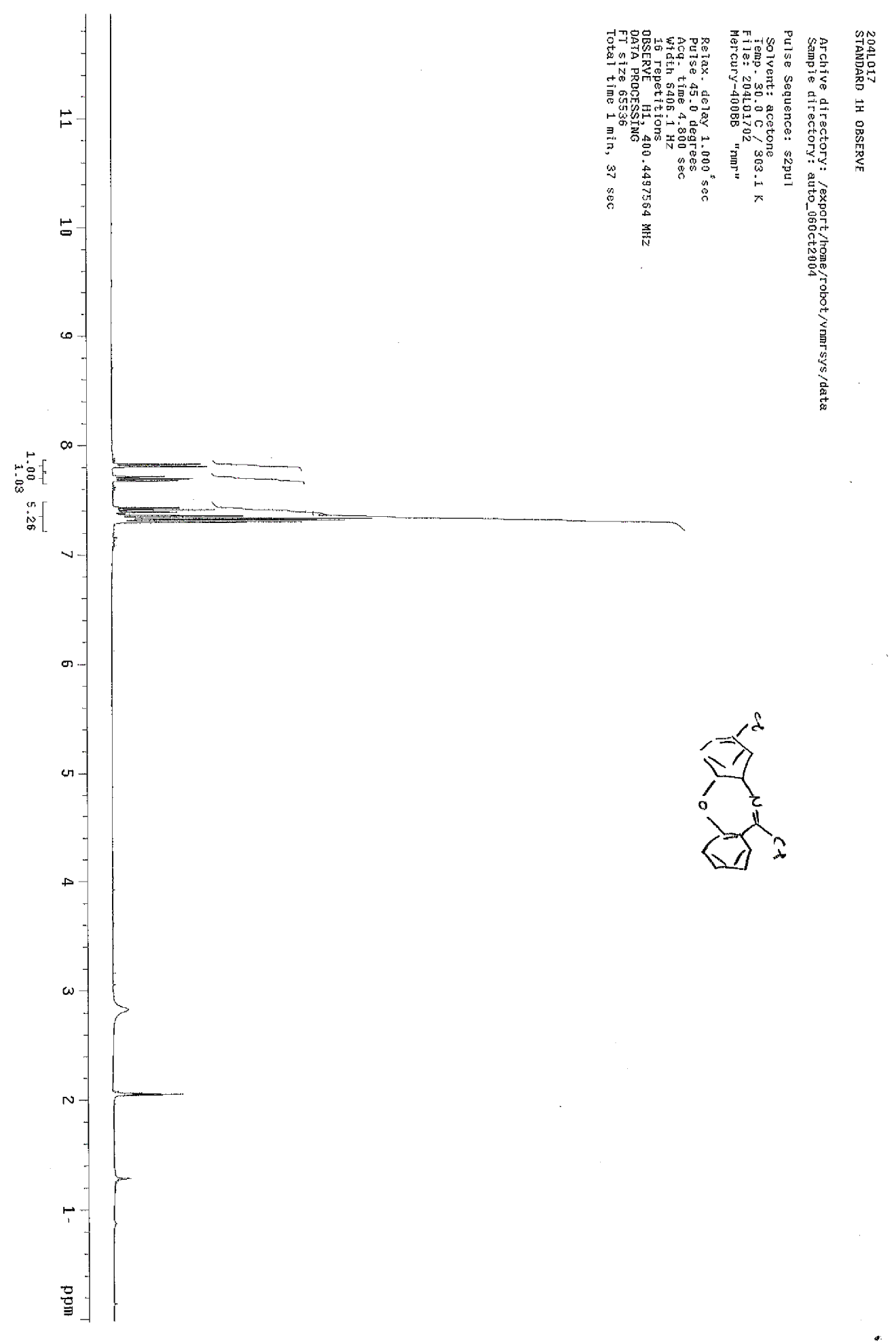



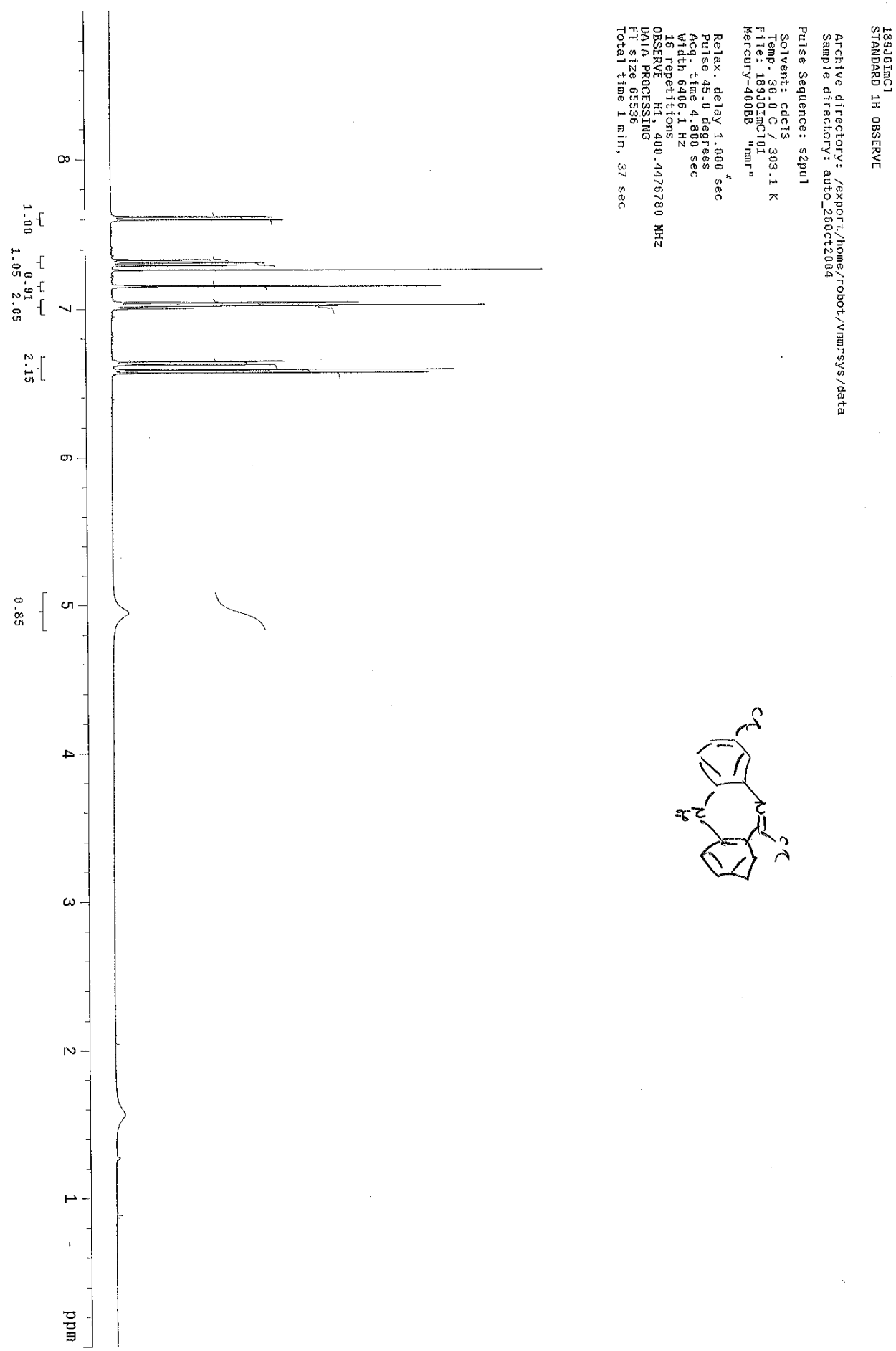


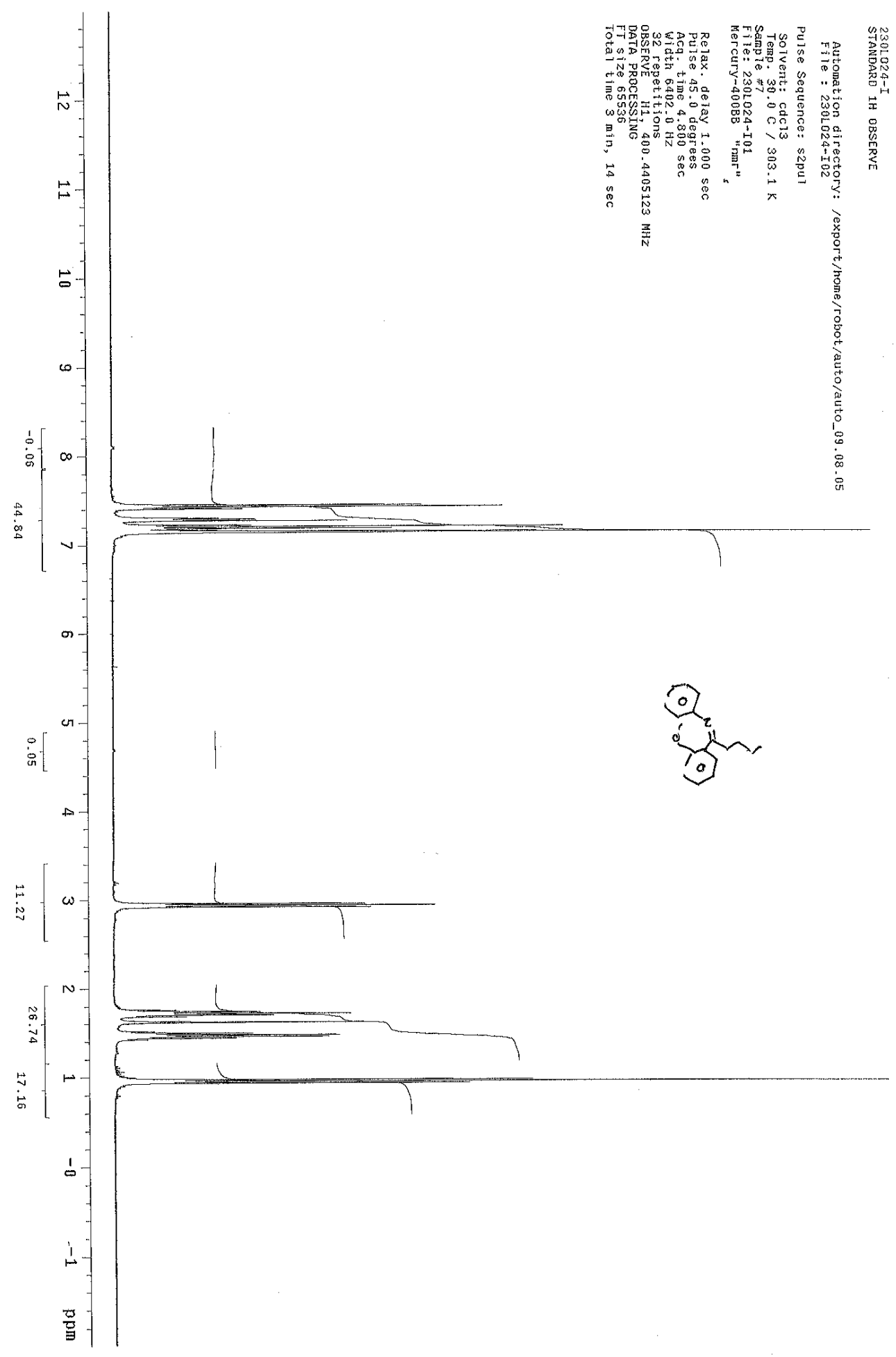




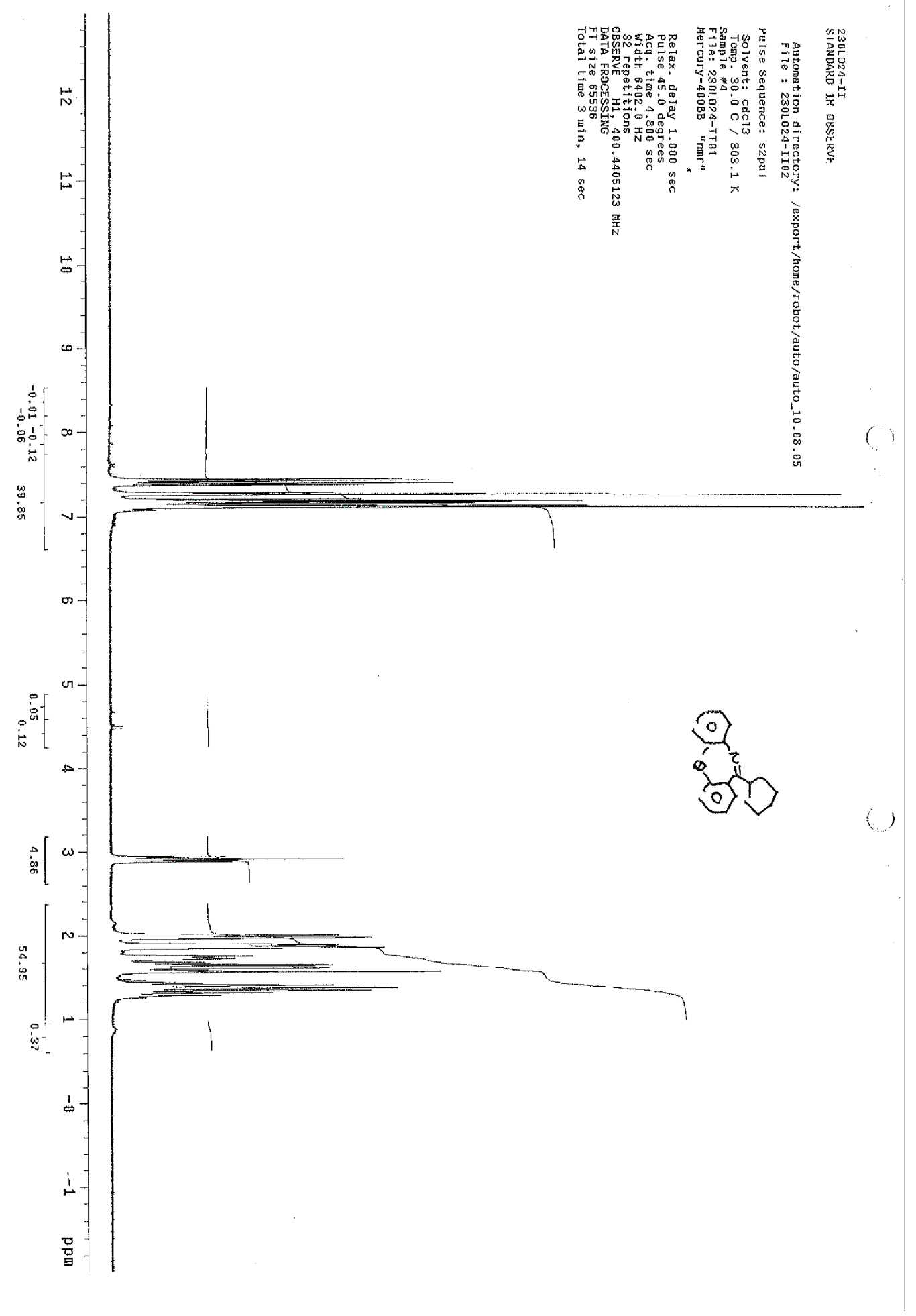




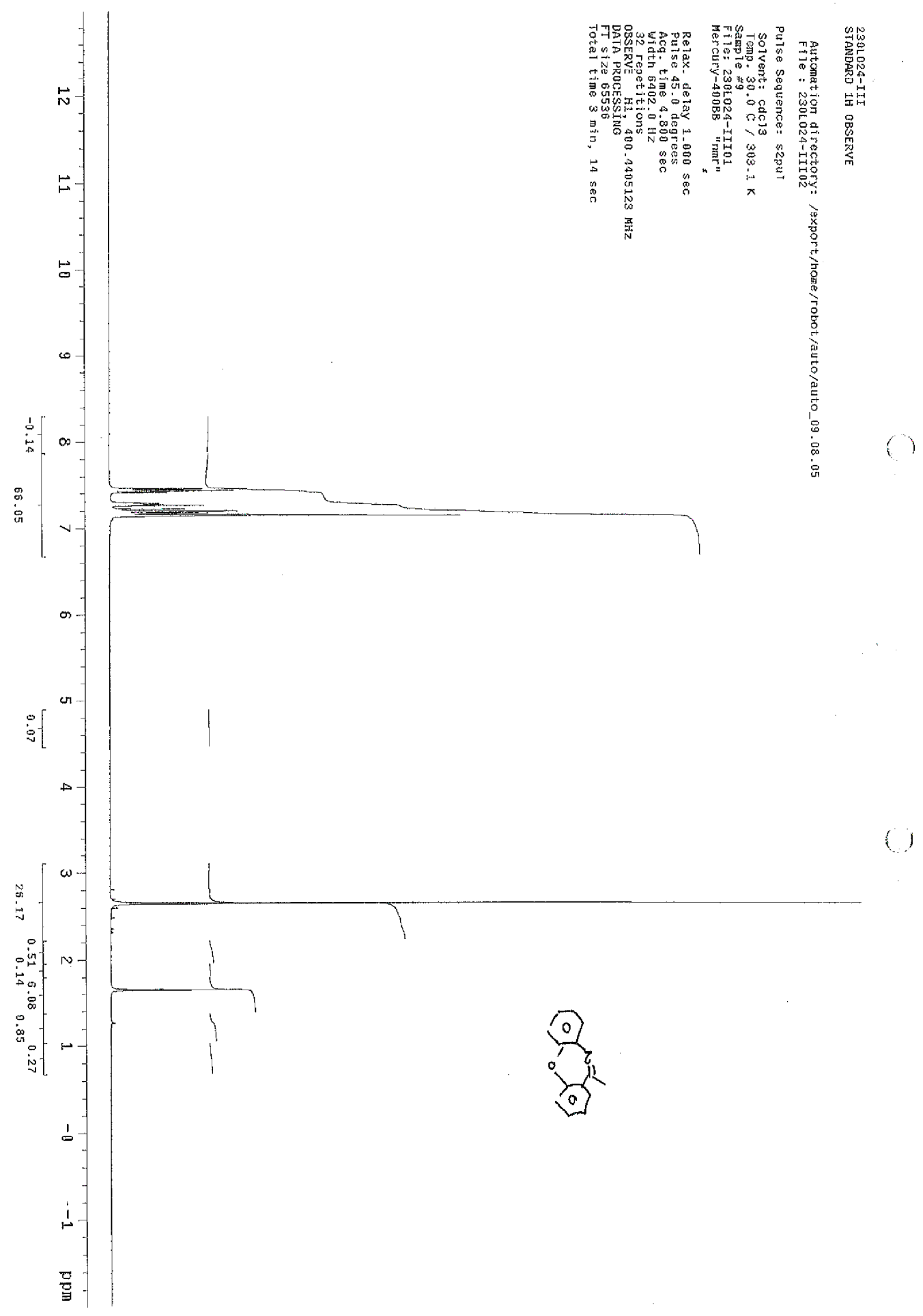




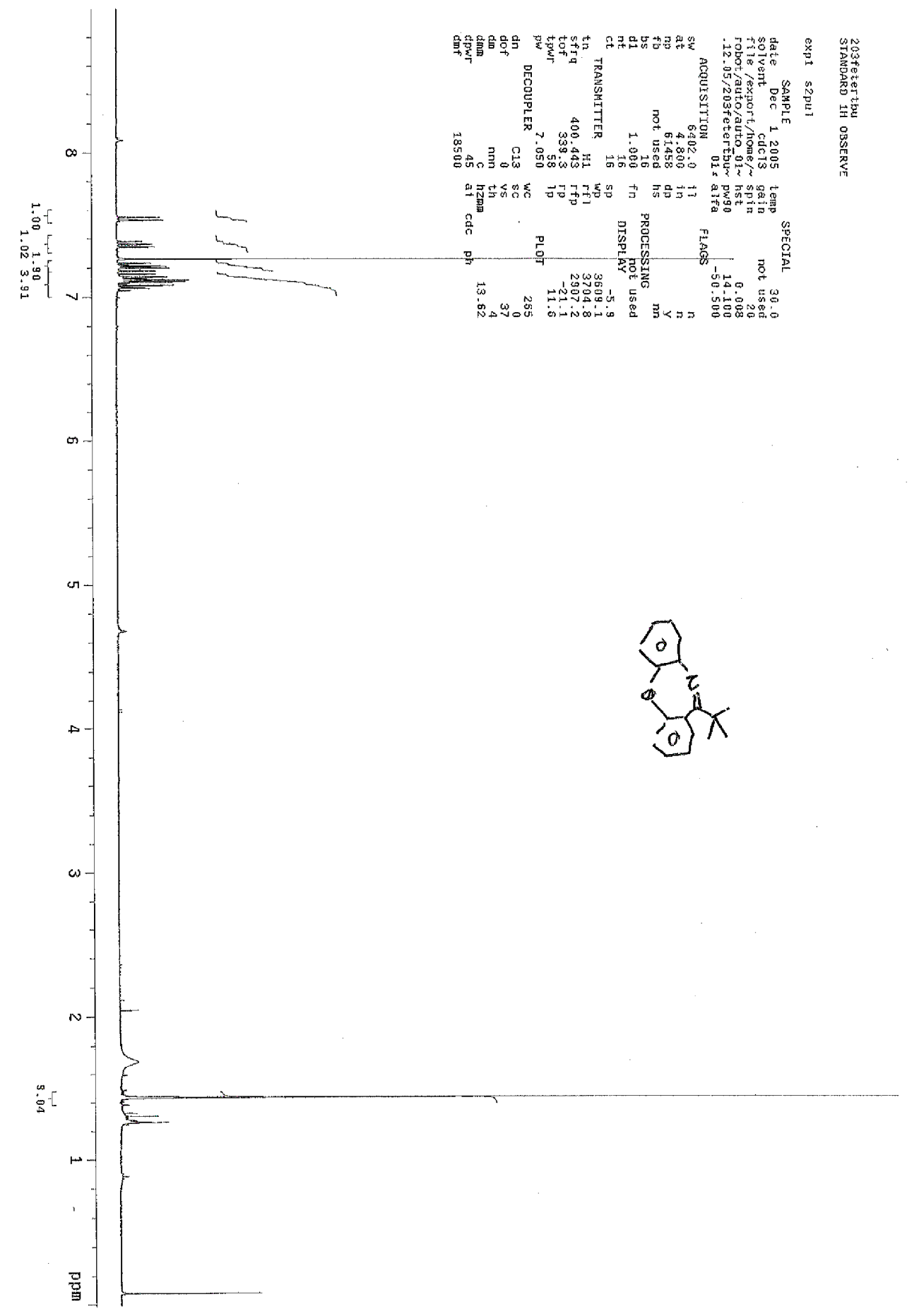




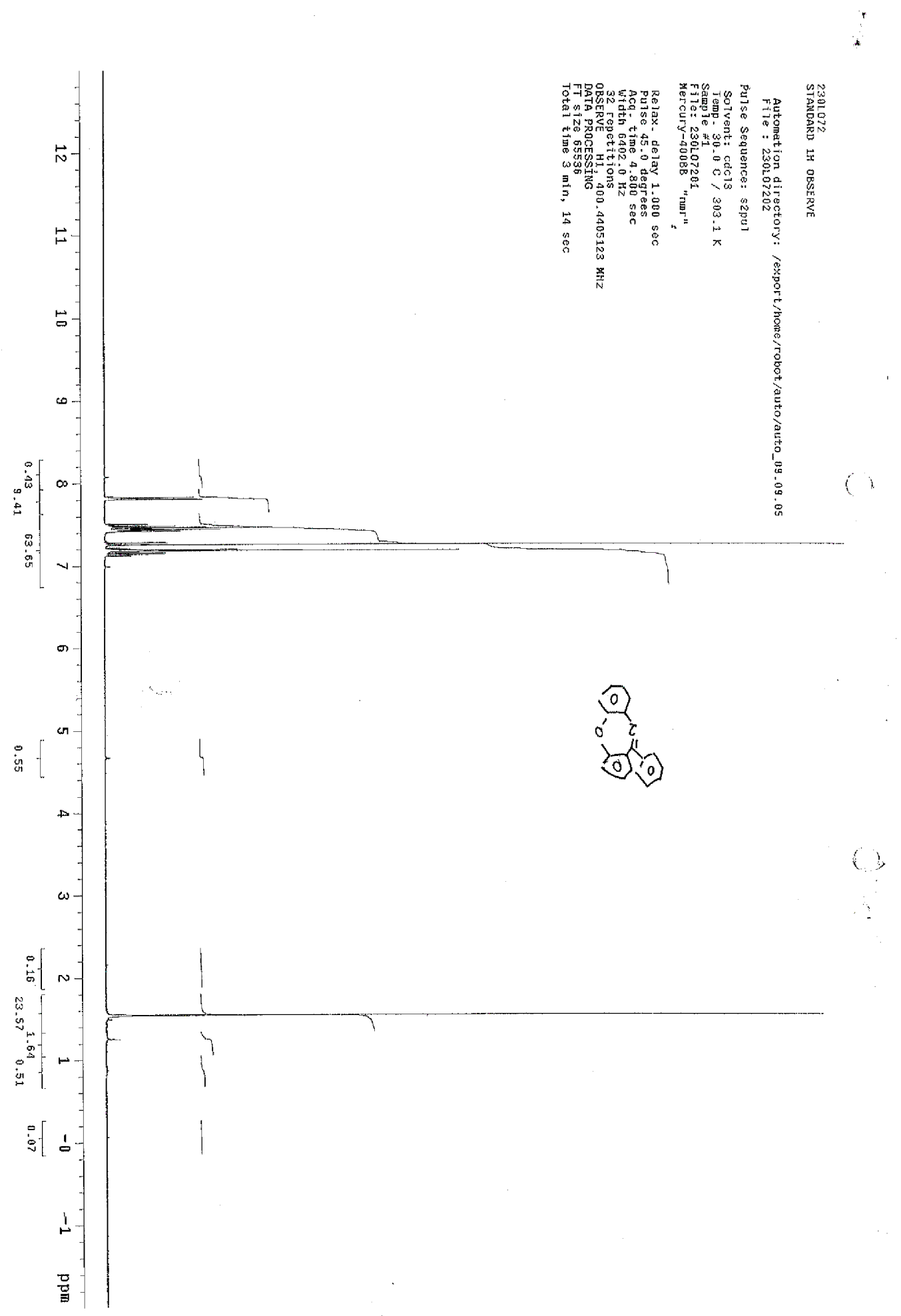




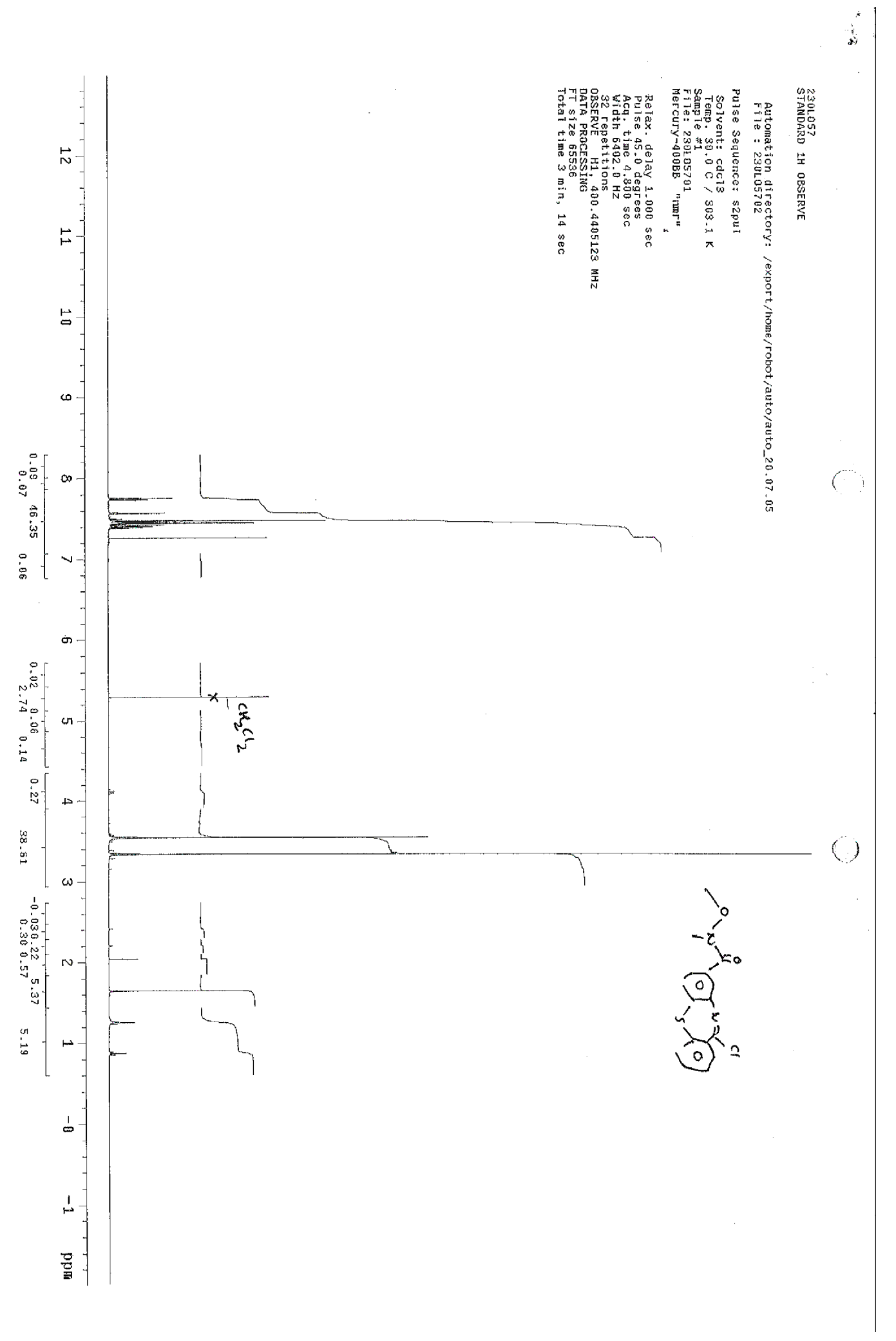




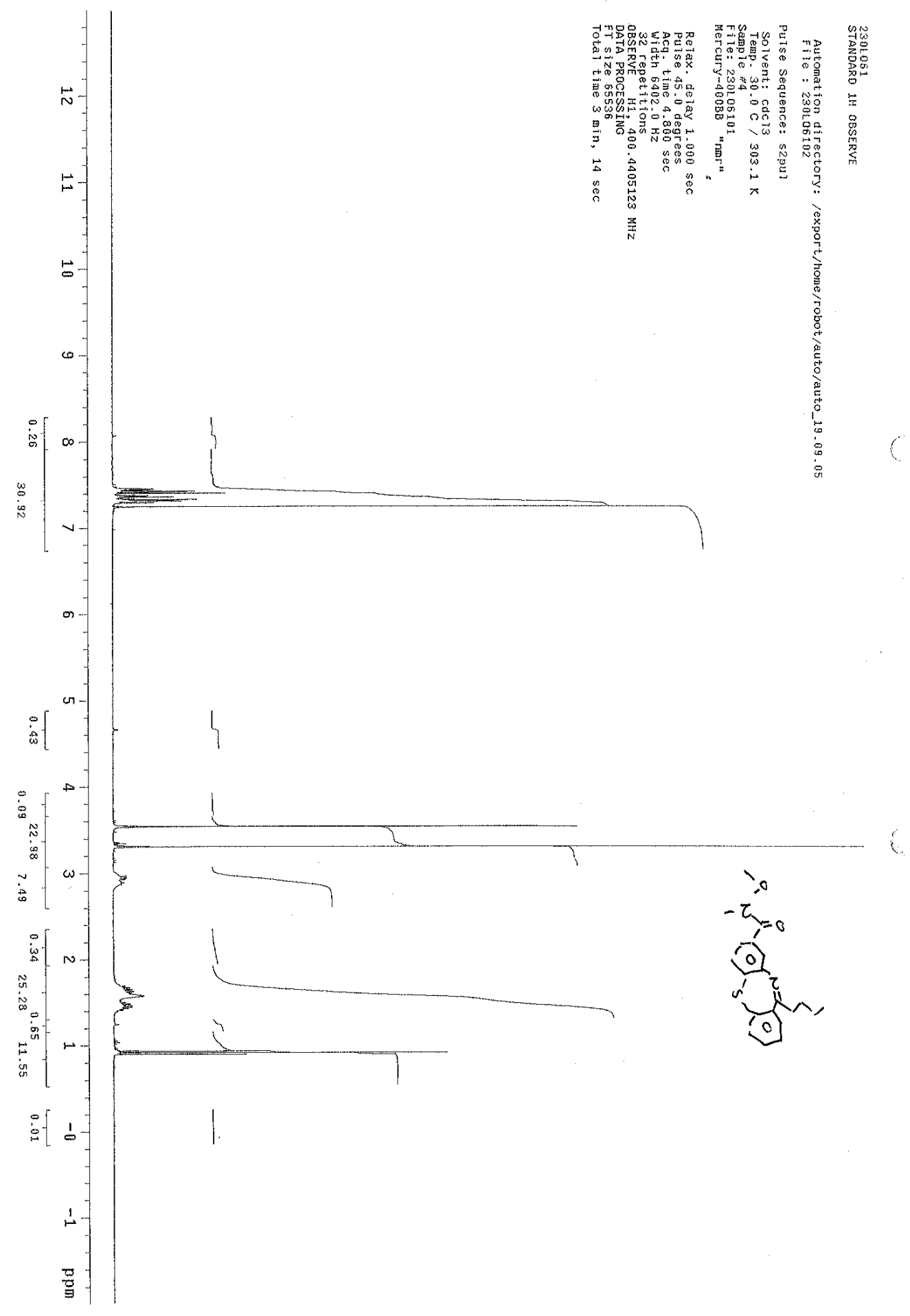




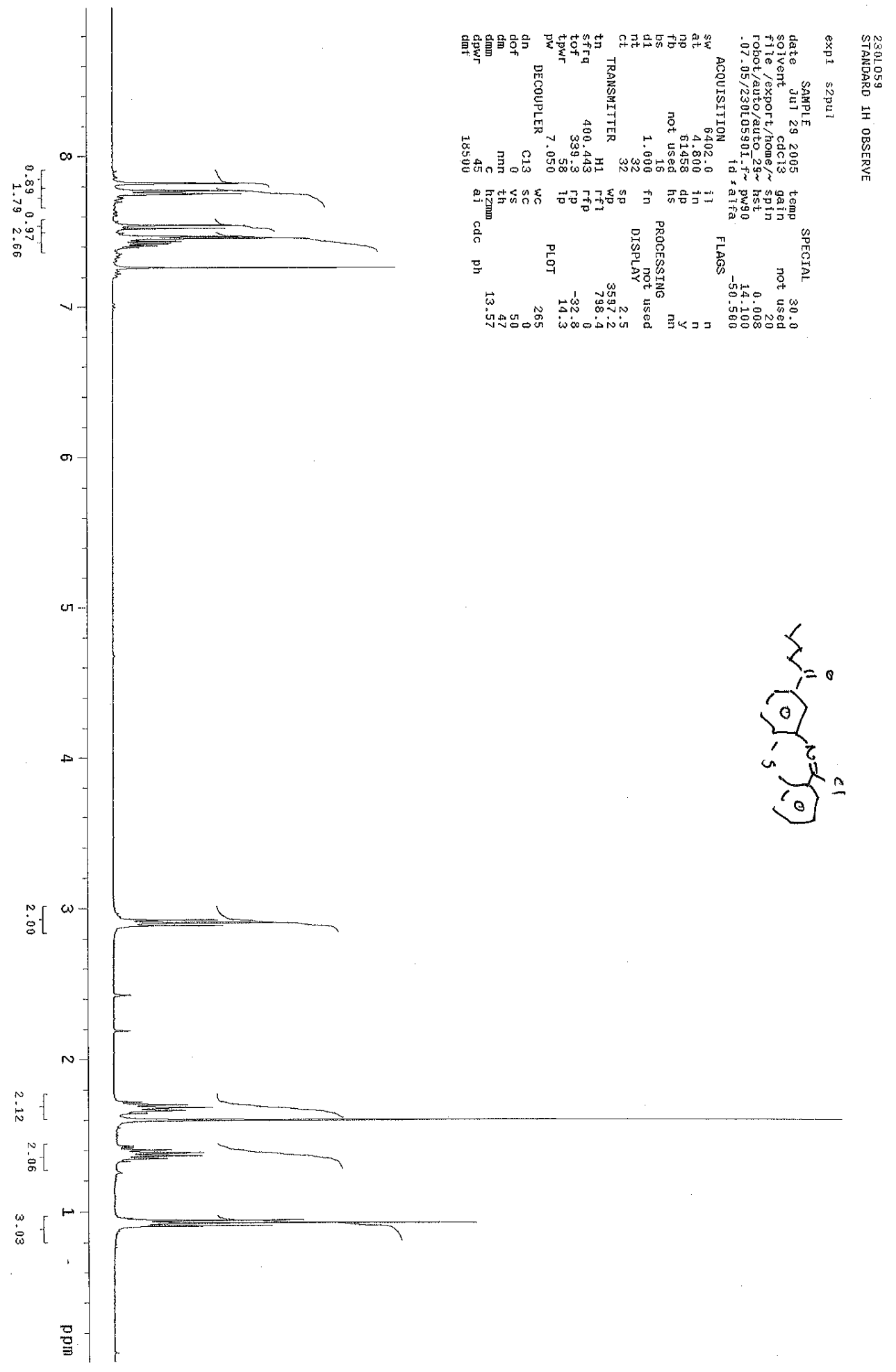




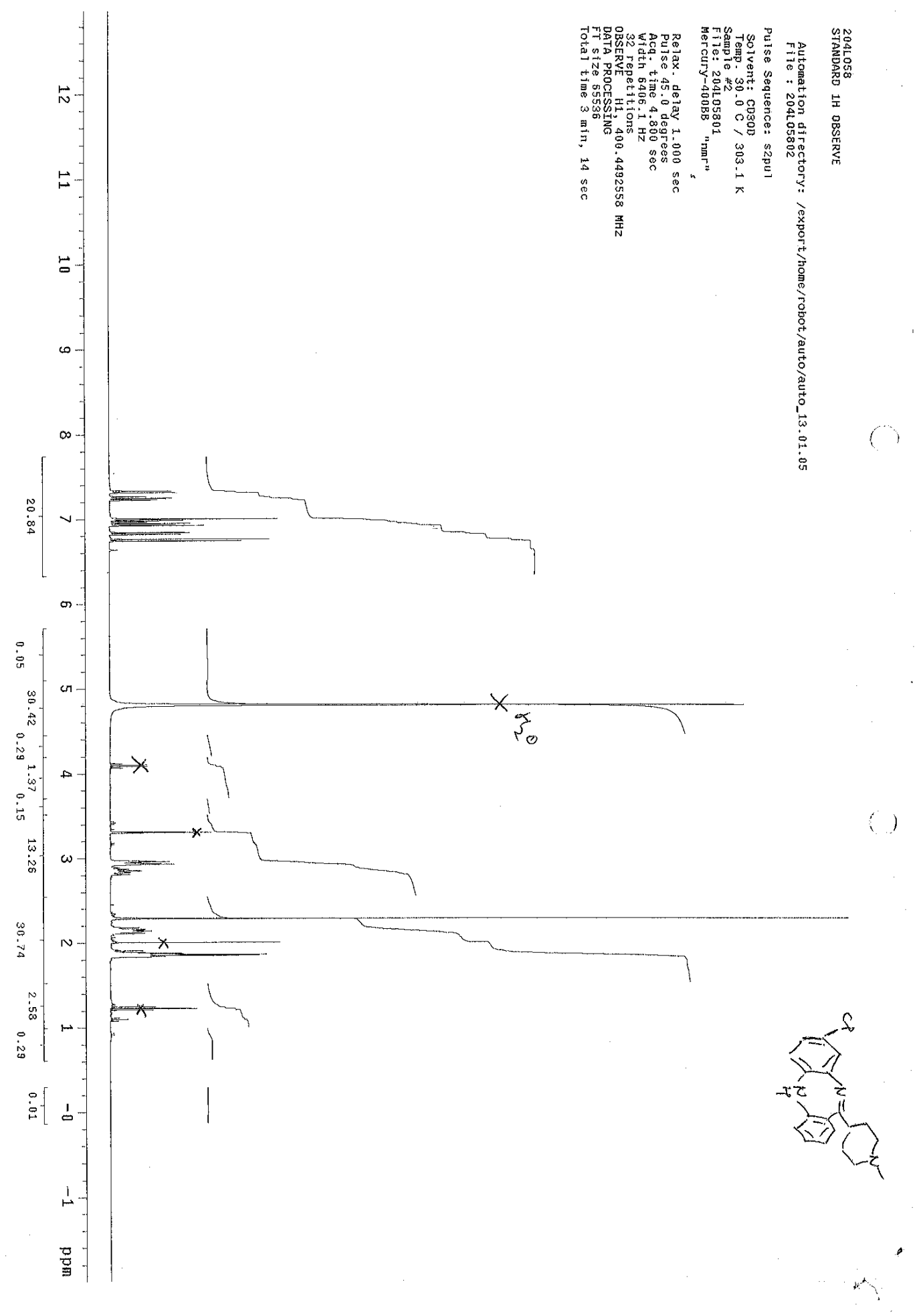




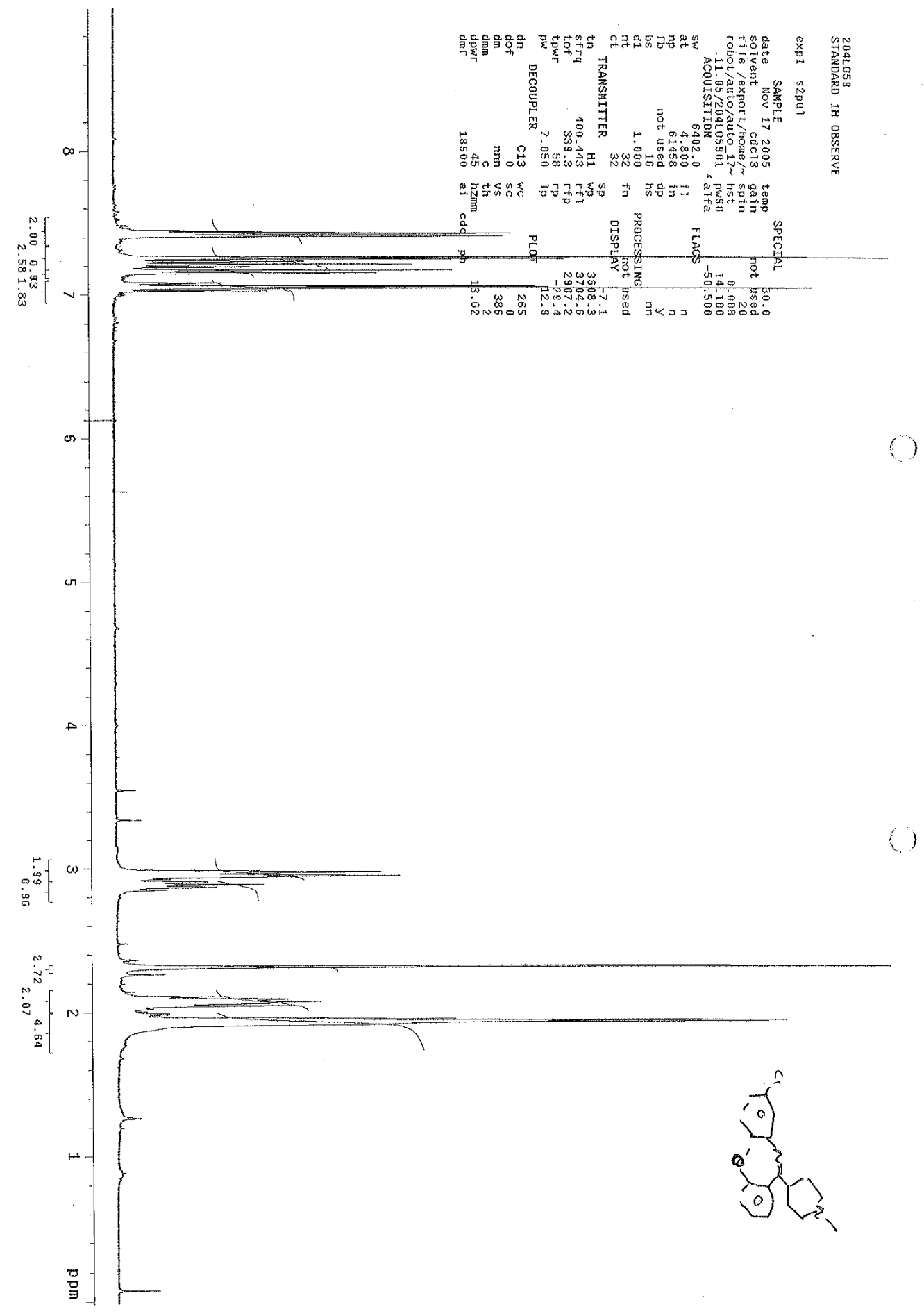




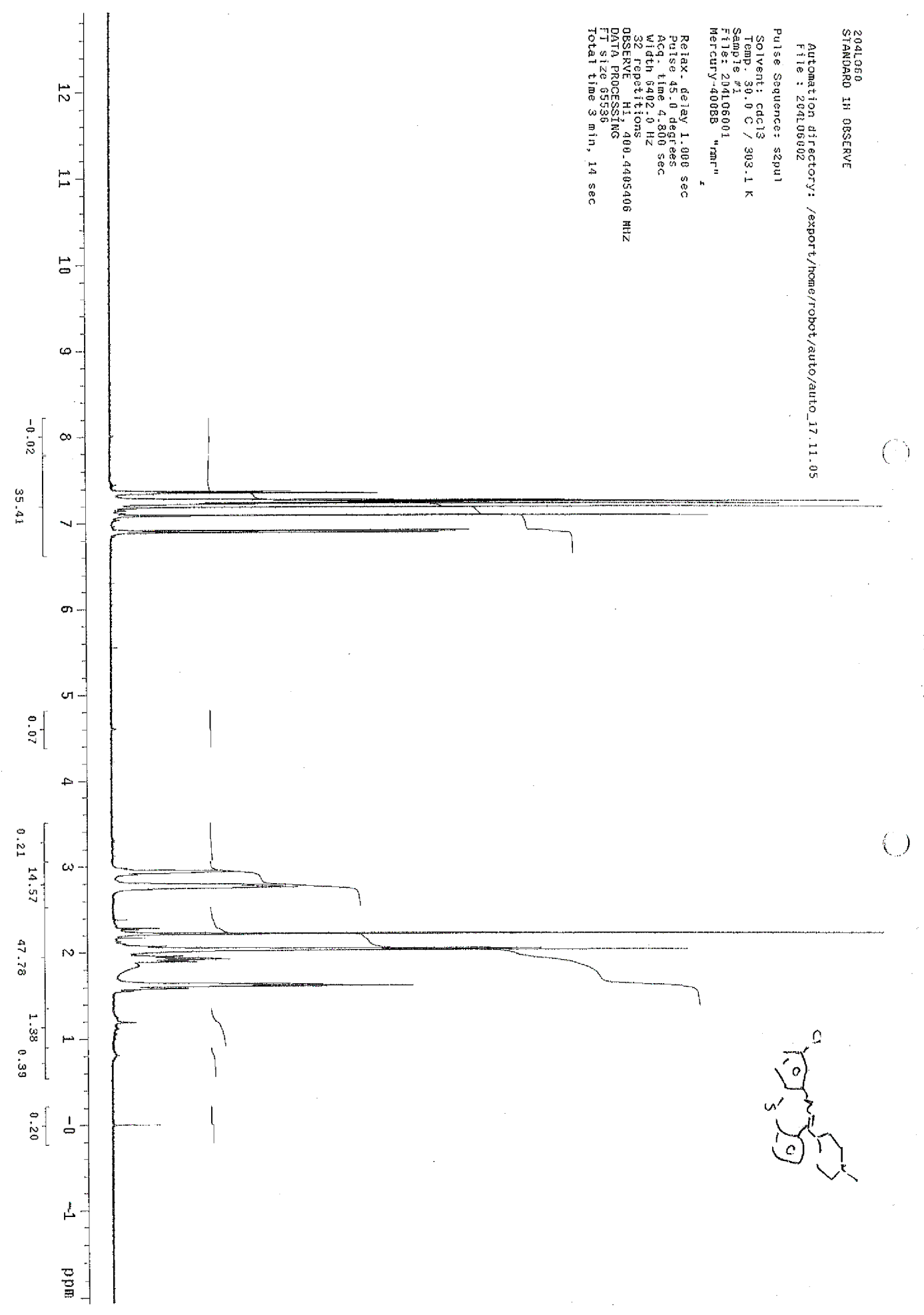




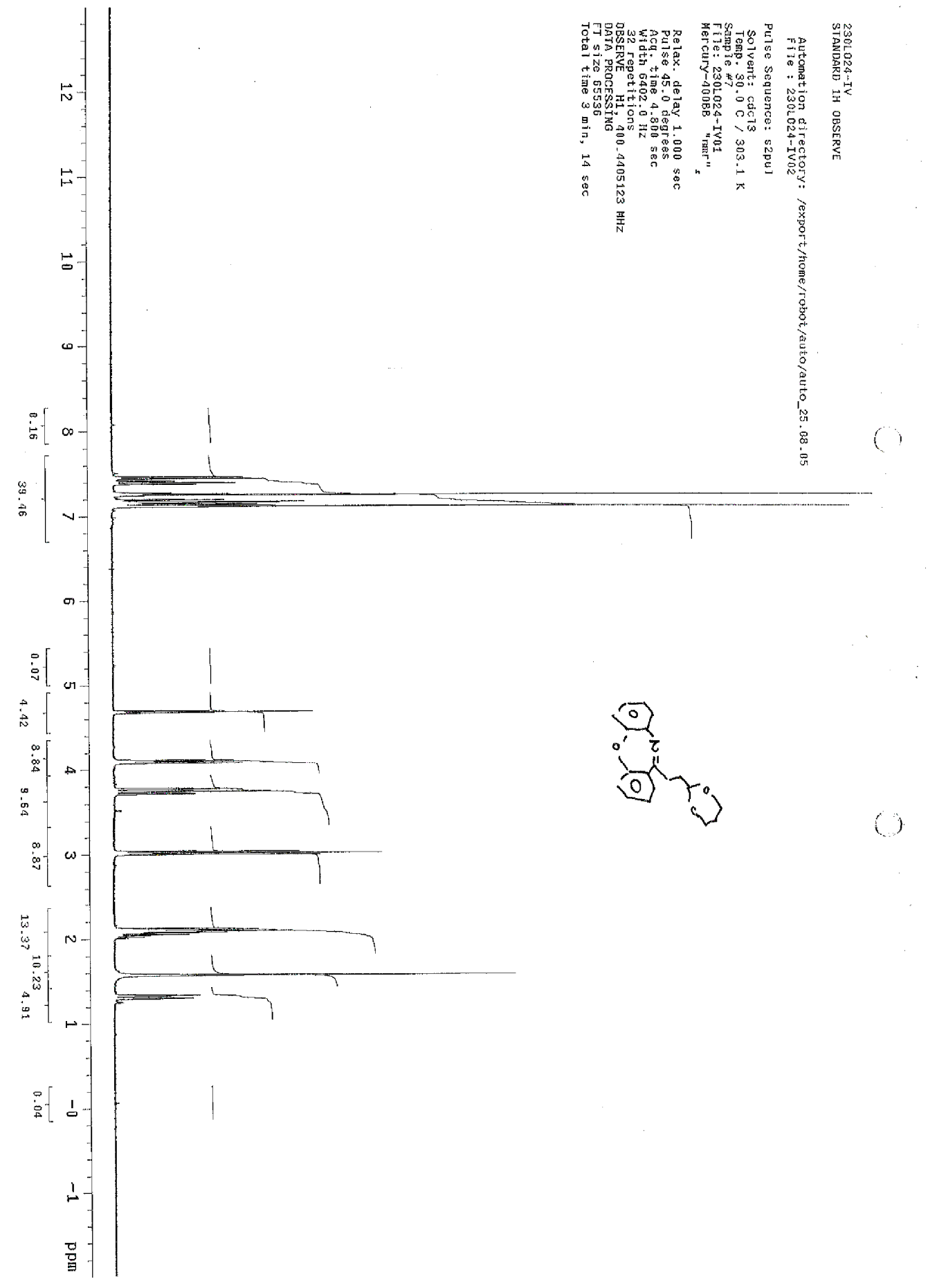

